\title{
MOLECULAR BEAM EPITAXY
}

MRS co-sponsors Third International Conference August 1 - 3

The Society is co-sponsor of the Third International Conference on Molecular Beam Epitaxy, to be held in San Francisco Aug. 1-3. The meeting is a major forum for the exchange of information on important new results in fundamental and applied research in molecular beam epitaxy.

Conference Chairman A.Y. Cho of Bell Laboratories said that among the topics to be discussed are semiconductor, metal and insulator; thermodynamic and kinetic aspects; growth and doping characteristics; metallurgical and electronic properties; surface and interface studies; heterostructure and superlattice; microwave and digital devices; optoelectronic devices, and equipment designs.

Cho said the meeting co-chairmen are L.L. Chang of IBM at Yorktown Heights (an MRS Councillor), B.A. Joyce of Redhill and K. Takahashi of Tokyo.

The Program Committee, chaired by H. Morkoc of Urbana, includes J.C.
Bean of Murray Hill, A.R. Calawa of Lexington, K.Y. Cheng of Tao-yuan, A.C. Gossard of Murray Hill, J. Massies of Valbonne, C.W. Litton of Wright-Patterson, K. Ploog of Stuttgart, H. Sakaki of Tokyo, Y. Shiraki of Kokubunji, W.T. Tsang of Murray Hill, C.E.C. Wood of Wembley and J. Woodall of Yorktown Heights.

The Local Chairman is D.M. Collins of Palo Alto. Publication Chairman is J.R. Arthur of Corvallis. Treasurer is P.D. Coleman of Urbana.

Other sponsoring organizations are the Institute of Electrical and Electronics Engineers, the American Physical Society, the American Vacuum Society and the Office of Naval Research.

MRS members are entitled to a reduced fee of $\$ 140$ to attend the conference, which will be held at the San Francisco Hilton and Tower.

For further information, contact Cho at Bell Labs, 600 Mountain Ave., Murray Hill, NJ 07974.

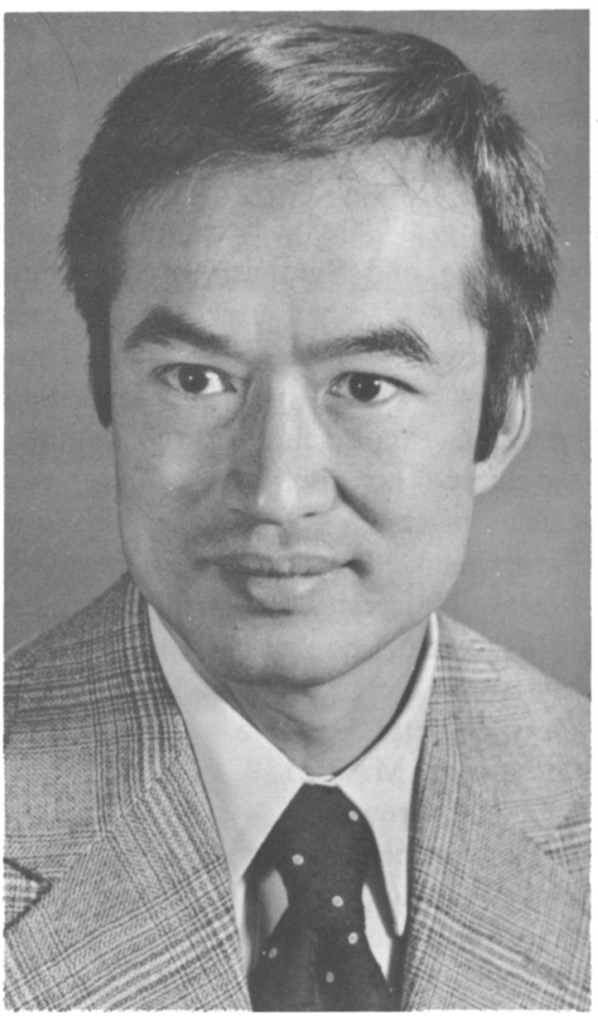

A.L. Cho 